\title{
Vacuna contra el SARS-CoV-2 (COVID-19) y enfermedad renal crónica
}

\author{
Victoria Sancha-Escudero ${ }^{1}$, José Luis Cobo-Sánchez ${ }^{1}$, Noelia Mancebo-Salas ${ }^{2}$, Raquel Pelayo-Alonso², \\ Zulema Gancedo-González ${ }^{1}$ \\ ${ }^{1}$ Subdirección de Cuidados. Servicio Cántabro de Salud. Santander. España \\ ${ }^{2}$ Escuela Universitaria de Enfermería Cruz Roja Española. Universidad Autónoma de Madrid. Madrid. España \\ ${ }^{3}$ Servicio de Nefrología. Hospital Universitario Marqués de Valdecilla. Santander. España
}

\begin{abstract}
Como citar este artículo: Sancha-Escudero V, Cobo-Sánchez JL, Mancebo-Salas N, Pelayo-Alonso R, Gancedo-González Z. Vacuna contra el SARS-CoV-2 (COVID-19) y enfermedad renal crónica.

Enferm Nefrol. 2021 Abr-Jun;24(2):117-27
\end{abstract}

\section{Resumen}

La literatura más reciente indica que la enfermedad renal crónica constituye la comorbilidad con mayor riesgo de desarrollar enfermedad grave por SARS-CoV-2, coronavirus 2019 (COVID-19). Muchas sociedades científicas se han posicionado a favor de la vacunación de los pacientes con enfermedad renal crónica como prioritaria, debido a esta alta vulnerabilidad. En España, la quinta actualización de la Estrategia de vacunación frente a COVID-19 del Consejo Interterritorial de Salud, incluyó a los pacientes con ERC dentro del grupo 7 (personas con condiciones de muy alto riesgo). A lo largo del artículo se describen los tipos de vacunas según mecanismo de acción, las vacunas actualmente aprobadas por la Agencia Europea del Medicamento (EMA) y todo lo relacionado con el proceso de vacunación (preparación, administración y seguimiento), además de los aspectos a tener en cuenta en los pacientes con enfermedad renal crónica.

PALABRAS CLAVE: vacunas COVID-19; diálisis renal; insuficiencia renal crónica; vacunación.

\section{Correspondencia:}

Victoria Sancha Escudero

Email: victoria.sancha@scsalud.es

\section{SARS-CoV-2 vaccine (COVID-19) and chronic kidney disease}

\begin{abstract}
The most recent evidence indicates that chronic kidney disease is the comorbidity with the highest risk of developing severe disease due to SARS-CoV-2, coronavirus 2019 (COVID-19). Many scientific societies have advocated for vaccination of patients with chronic kidney disease as a priority, due to this high vulnerability. In Spain, the fifth update of the COVID-19 vaccination strategy published by the Interterritorial Health Council included CKD patients in group 7 (people with very highrisk conditions). This manuscript describes the types of vaccines according to mechanism of action, the vaccines currently approved by the European Medicines Agency (EMA) and information related to the vaccination process (preparation, administration and follow-up), as well as aspects to be taken into account in patients with CKD.
\end{abstract}

KEYWORDS: COVID-19 vaccines; renal dialysis; chronic kidney disease; vaccination. 


\section{Introducción}

La literatura más reciente indica que la enfermedad renal crónica (ERC) constituye la comorbilidad con mayor riesgo de desarrollar enfermedad grave por SARS-CoV-2, coronavirus 2019 (COVID19)1. La ERC explica el aumento del riesgo de COVID-19 grave para aproximadamente uno de cada cuatro individuos de alto riesgo en todo el mundo, equivalente al 5\% de la población mundial, o 86.530 .000 personas ${ }^{2}$. Williamson y cols. ${ }^{3}$ publicaron recientemente el análisis más grande hasta la fecha de los factores de riesgo de COVID-19 grave con resultado de muerte. De este estudio se desprende que la ERC avanzada (grados 4 y 5) se encontraba entre las condiciones que conllevaban el mayor riesgo de muerte: el riesgo relativo de muerte en pacientes en diálisis era de 3,69, en pacientes trasplantados renales de 3,52 y en pacientes con ERC estadíos 4 y 5 (filtrado glomerular estimado $<30 \mathrm{~mL} / \mathrm{min} / 1,73 \mathrm{~m}^{2}$ ) de 2,52; mientras que en pacientes diabéticos el riesgo relativo de muerte oscilaba entre 1,31 a 1,95 (dependiendo del control glucémico), y en pacientes con enfermedad cardiaca crónica bajaba a 1,17.

Debido a esta alta vulnerabilidad y a la alta exposición de los pacientes en hemodiálisis en centro (transporte colectivo y acudir a un centro al menos 3 veces por semana), que imposibilita el distanciamiento social y el confinamiento reglamentario; además de la inmunodepresión inherente a la ERC (acentuada en los pacientes trasplantados), muchas sociedades científicas se han posicionado a favor de la vacunación de los pacientes con ERC como prioritaria ${ }^{4-7}$.

En España, la quinta actualización de la Estrategia de vacunación frente a COVID-19 del Consejo Interterritorial de Salud (EVCCISE) ${ }^{8}$, incluyó a los pacientes con ERC dentro del grupo 7 (Personas con condiciones de muy alto riesgo). La actualización 6 de la EVCCISE indica que: "Las personas con condiciones de muy alto riesgo a partir de 16-18 años se vacunarán de forma paralela a las personas del grupo 5B (personas entre 70 y 79 años de edad), si no les corresponde antes por grupo de edad. Se utilizará cualquiera de las vacunas autorizadas, pero preferentemente vacunas de ARNm, manteniendo el intervalo de 21 o 28 días (según se trate de Comirnaty o vacuna de Moderna, respectivamente) $)^{\prime \prime 9}$.

\section{Tipos de vacuna según mecanismo de acción}

En función de su mecanismo de acción, en la actualidad podemos describir los siguientes tipos de vacuna contra la COVID-1910,11:
- Vacunas inactivadas y de subunidades proteicas. Un enfoque para el desarrollo de vacunas es la creación de vacunas inactivadas derivadas de virus cultivados y luego inactivados químicamente, que pueden liberar epítopos antigénicos conformacionalmente nativos expresados de manera estable.

- Vacunas de vectores virales. Las vacunas de vectores virales utilizan virus de replicación deficiente diseñados para expresar la secuencia genética del antígeno de interés en las células huésped.

- Vacunas de ARN mensajero. En estas vacunas, las nanopartículas de lípidos se utilizan para proteger el ARNm que codifica la proteína $S$ estabilizado por prefusión en ruta hacia el espacio intracelular. El huésped usa el ARNm para producir la proteína diana (proteína $S$ en este caso), que induce una respuesta inmune coordinada.

- Vacunas basadas en proteínas. Utilizan fragmentos inocuos de proteínas o estructuras proteínicas que imitan el virus causante de la COVID-19 con el fin de generar una respuesta inmunitaria.

\section{Vacunas aprobadas por la Agencia Europea del Medicamento (EMA)}

En la actualidad, las vacunas aprobadas por la Agencia Europea del Medicamento contra la COVID-19 son:

\section{Vacuna COMIRNATY ${ }^{\circledR}$ (Pfizer-BioNTech) ${ }^{12,13}$}

Es una vacuna de ARN mensajero monocatenario, con caperuza en el extremo $5^{\prime}$ que codifica la proteína $S$ (espícula) del virus SARS-CoV-2. Pauta de dosis: 2 dosis de $0,3 \mathrm{ml}(30 \mu \mathrm{g})$. La Agencia Española de Medicamentos y Productos Sanitarios (AEMPS) considera que la segunda dosis se puede administrar, al menos a los 19 días de la primera dosis; habitualmente, entre 21 y 28 días después de la primera sin que esto influya en su grado de eficacia. No se dispone de datos sobre la intercambiabilidad con otras vacunas frente a la COVID-19 para completar la serie de vacunación. Eficacia global: $52 \%$ tras la primera dosis (IC:95\%: $29,5 \%-68,4 \%$ ); $94,6 \%$ a los 7 días tras la segunda dosis (IC:95\%: $89,9 \%-97,3 \%)^{10}$.

\section{Vacuna mRNA-1273 ${ }^{\circledR}$ (Moderna) $)^{14,15}$}

Es una vacuna de ARN mensajero monocatenario con casquete en $5^{\prime}$ producido mediante una transcripción in vitro libre de células a partir de las correspondientes 
plantillas de ADN, que codifica la proteína de pico (S) viral del SARS-CoV-2. Pauta de dosis: 2 dosis de 0,5 $\mathrm{ml}(100 \mu \mathrm{g})$. La segunda dosis puede administrarse a los 28 días después de la primera dosis. No se dispone de datos sobre la intercambiabilidad de esta vacuna con otras vacunas frente a la COVID-19 para completar la serie de vacunación. Eficacia global: $92,1 \%$ a los 14 días tras la primera dosis (IC:95\%: 68,8\%-99,1\%); $94,1 \%$ a los 14 días tras la segunda dosis (IC:95\%: $89,3 \%-96,8 \%)^{10}$.

\section{Vacuna Vaxzevria ${ }^{\circledR}$ (AstraZeneca) $)^{16,17}$}

Vacuna basada en un vector viral (adenovirus de chimpancé) no replicante con genes que codifican la expresión de la proteína S completa de SARS-CoV-2 en superficie. Pauta de dosis: dos dosis de $0,5 \mathrm{ml}\left(5 \times 10^{10}\right.$ partículas virales). La segunda dosis se administra entre 10 y 12 semanas, preferiblemente a las 12 semanas, pues se ha apreciado una eficacia más elevada 9 . Aunque inicialmente el Consejo Interterritorial decidió paralizar temporalmente la vacunación con Vaxzevria (Astrazaneca), el 19 de mayo acordó que aquella población que hubiera sido vacunada con una primera dosis de la citada vacuna, pudieran recibir una segunda dosis previa firma de un consentimiento informado ${ }^{18}$. Para ello se realizó además una consulta al Comité de Bioética de España que concluyó, que todas aquellas personas que manifestaran su rechazo a ser vacunadas con una pauta heteróloga pudieran solicitar y recibir una segunda dosis de la vacuna Vaxzevia previa firma de un protocolo de consentimiento informado específico asegurando así su propia salud, y la colectiva ${ }^{19}$. A mayo del corriente, el Consejo Interterritorial ha decidido paralizar temporalmente la vacunación con AstraZeneca en menores de 60 años, retrasando la segunda dosis de 12 a 16 semanas, por tanto de momento solo se administrará a personas entre 60 y 69 años 9 . Eficacia global: $64,1 \%$ tras la primera dosis (IC: $95 \%: 50,5 \%-73,9 \%$ ); $70,4 \%$ a los 14 días tras la segunda dosis (IC:95\%: $54,8 \%-80,6 \%)^{10}$.

\section{Vacuna Ad26.COV2S ${ }^{\circledR}$ (Janssen) $^{20,21}$}

Es una vacuna monovalente recombinante compuesta por un vector de adenovirus tipo 26 humano no replicativo que codifica una glucoproteína de la espícula (S) de longitud completa del SARS-CoV-2 en una conformación estabilizada. Tras la administración, la glucoproteína S del SARS-CoV-2 se expresa de manera transitoria, estimulando tanto los anticuerpos neutralizantes como otros anticuerpos funcionales específicos anti-S, así como respuestas inmunes celulares dirigidas contra el antígeno $\mathrm{S}$, que pueden contribuir a la protección frente a COVID-19. Pauta de dosis: una única dosis de $0,5 \mathrm{ml}$ $\left(8,92 \log ^{10}\right.$ unidades infecciosas). Eficacia global: A los 28 días, $72 \%$ en Estados Unidos; $66 \%$ in América Latina y $57 \%$ en Sudáfrica ${ }^{10}$.

En la Tabla 1 se resumen las precauciones de almacenamiento y conservación de estas 4 vacunas ${ }^{12-17,20,21}$.

\section{Administración de las vacunas}

El vial debe diluirse en máximas condiciones de asepsia, su conservación posterior es responsabilidad del profesional sanitario. El área de trabajo debe estar limpia y desinfectada. Los profesionales implicados directamente en la vacunación deben estar vacunados correctamente o haberse comprobado su inmunización previa ${ }^{22}$.

Las manos deben limpiarse con solución hidroalcohólica o agua y jabón antes de la preparación de la vacuna, entre pacientes, etc ${ }^{23}$.

El haber utilizado guantes no exime de realizar la correcta higiene de manos tras su retirada. Si las manos están visiblemente limpias, la higiene de manos se realizará con soluciones hidroalcohólicas o desinfectantes con actividad virucida; si hay suciedad visible o manchadas con fluidos se realizará con agua y jabón antiséptico. Hay que favorecer el ajuste de la mascarilla autofiltrante al rostro, comprobando su correcto sellado. La barba hace que sea imposible sellar bien la mascarilla al rostro ${ }^{24,25}$. Las uñas deben llevarse cortas y cuidadas, no pudiendo usar anillos, pulseras, relojes de muñeca u otros adornos.

No tocarse los ojos, la boca ni el teléfono móvil, en caso de hacerlo lavarse de inmediato las manos. En caso de toser o estornudar, cubrirse con el codo o con pañuelos desechables que deben ser eliminados de inmediato. Utilizar el cabello recogido en su totalidad y zapatos cerrados $^{26}$.

Se debe informar en el punto de vacunación del nombre de la vacuna que se administra y verificar los antecedentes del paciente: alergias, enfermedades, posibilidad de embarazo o lactancia.

En la particularidad de la vacunación de personas que tengan limitada la capacidad para tomar decisiones es conveniente la información y autorización por escrito por parte del representante legal o personas vinculadas a él o ella por razones familiares o de hecho. En los casos 
Tabla 1. Resumen las precauciones de almacenamiento y conservación de las vacunas aprobadas hasta el momento por la Agencia Europea del Medicamento (EMA).

\begin{tabular}{|c|c|c|c|c|c|}
\hline \multirow[t]{2}{*}{ Característica } & & \multicolumn{4}{|c|}{ Vacuna } \\
\hline & & Vacuna COMIRNATY® & Vacuna mRNA-1273 ${ }^{\circledR}$ & Vacuna Vaxzevria $^{\circledR}$ & Vacuna Ad26.CoV2.S ${ }^{\circledast}$ \\
\hline Fabricante & & Pfizer-BioNTech & Moderna & AstraZeneca & Janssen/Johnson \& Johnson \\
\hline Tipo de vacuna & & ARN mensajero & ARN mensajero & Vector Viral & Vector Viral \\
\hline Pauta de dosis & & $\begin{array}{l}2 \text { dosis de } 0,3 \mathrm{ml} \\
(30 \mu \mathrm{g}) \text {, separadas entre } \\
21 \text { y } 28 \text { días }\end{array}$ & $\begin{array}{l}2 \text { dosis de } 0,5 \mathrm{ml} \text { ( } 100 \\
\mu \mathrm{g}) . \text { La segunda dosis } \\
\text { puede administrarse a } \\
\text { partir de los } 28 \text { días tras } \\
\text { la primera dosis }\end{array}$ & $\begin{array}{l}\text { Dos dosis de } 0,5 \mathrm{ml} \\
\text { ( } 5 \times 1010 \text { partículas } \\
\text { virales) separadas entre } \\
4 \text { y12 semanas }\end{array}$ & $\begin{array}{l}\text { Una única dosis de 0,5 ml } \\
(8,92 \log 10 \mathrm{u})\end{array}$ \\
\hline Almacenamiento & & $\begin{array}{l}\text { Ultracongelada entre } \\
-60^{\circ} \text { y }-90^{\circ} \mathrm{C} \text { o hasta la } \\
\text { fecha de caducidad }\end{array}$ & $\begin{array}{l}\text { El vial multidosis conge- } \\
\text { lado entre }-25^{\circ} \text { y }-15^{\circ} \mathrm{C} \\
\text { durante } 7 \text { meses o hasta } \\
\text { la fecha de caducidad. } \\
\text { No conservar en hielo } \\
\text { seco o por debajo de } \\
-40^{\circ} \mathrm{C}\end{array}$ & $\begin{array}{l}\text { El vial multidosis, sin } \\
\text { abrir, dura hasta } 6 \text { me- } \\
\text { ses en la nevera o hasta } \\
\text { la fecha de caducidad } \\
\text { entre } 2^{\circ} \text { y } 8^{\circ} \mathrm{C}\end{array}$ & $\begin{array}{l}\text { Congelada entre }-15^{\circ} \text { y } \\
-25^{\circ} \mathrm{C}: 2 \text { años o hasta la } \\
\text { fecha de caducidad }\end{array}$ \\
\hline Descongelación & $\begin{array}{l}\text { Nevera (de } 2 \text { a } 8^{\circ} \mathrm{C} \text { ) } \\
\text { Temperatura ambiente } \\
\text { Atención: cada } \\
\text { vacuna especifica } \\
\text { una temperatura } \\
\text { ambiente }\end{array}$ & $\begin{array}{l}3 \text { horas } \\
30 \text { minutos }\end{array}$ & $\begin{array}{l}2 \text { horas y } 30 \text { minutos } \\
1 \text { hora }\end{array}$ & No congelada & $\begin{array}{l}\text { Caja } 10 \text { viales: } 12 \text { horas } \\
\text { Vial individual: } 2 \text { horas } \\
\text { Caja } 10 \text { viales: } 2 \text { horas } \\
\text { Vial individual: } 1 \text { hora }\end{array}$ \\
\hline $\begin{array}{l}\text { Tiempos } \\
\text { máximos de uso }\end{array}$ & $\begin{array}{l}\text { Vial sin perforar } \\
\text { Vial abierto* }\end{array}$ & $\begin{array}{l}\text { Nevera (de } 2^{\circ} \text { a } 8^{\circ} \mathrm{C} \text { ): } \\
1 \text { mes } \\
\text { Temperatura ambiente } \\
\left(\text { de } 8^{\circ} \text { a } 25^{\circ} \mathrm{C} \text { ): } 2 \text { horas }\right. \\
\text { Nevera (de } 2^{\circ} \text { a } 8^{\circ} \mathrm{C} \text { ): } \\
6 \text { horas } \\
\text { Temperatura ambiente } \\
\text { (de } 8^{\circ} \text { a } 25^{\circ} \mathrm{C} \text { ): } 6 \text { horas }\end{array}$ & $\begin{array}{l}\text { Nevera (de } 2^{\circ} \text { a } 8^{\circ} \mathrm{C} \text { ): } \\
30 \text { días } \\
\text { Temperatura ambiente } \\
\left(\text { de } 8^{\circ} \text { a } 25^{\circ} \mathrm{C} \text { ): } 24 \text { horas }\right. \\
\text { Nevera (de } 2^{\circ} \text { a } 8^{\circ} \mathrm{C} \text { ): } 6 \\
\text { horas } \\
\text { Temperatura ambiente } \\
\left(\text { de } 8^{\circ} \text { a } 25^{\circ} \mathrm{C} \text { ): } 19 \text { horas }\right.\end{array}$ & $\begin{array}{l}\text { Usar dentro de las } 6 \\
\text { horas siguientes al } \\
\text { primer uso }\end{array}$ & $\begin{array}{l}\text { Nevera (de } 2 \text { a } 8^{\circ} \mathrm{C} \text { ): } 3 \\
\text { meses o hasta la fecha de } \\
\text { caducidad. } \\
\text { Temperatura ambiente } \\
\text { (máximo } 25^{\circ} \mathrm{C} \text { ): } 12 \text { horas. } \\
\text { Nevera }\left(\text { de } 2 \text { a } 8^{\circ} \mathrm{C} \text { ): } 6\right. \\
\text { horas } \\
\mathrm{T}^{\mathrm{a}} \text { ambiente (máx. } 25^{\circ} \mathrm{C} \text { ): } \\
3 \text { horas }\end{array}$ \\
\hline Precauciones & & $\begin{array}{l}\text { Tras la dilución en el } \\
\text { primer domicilio, los } \\
\text { viales se deben conser- } \\
\text { var entre } 2 \text { y } 30^{\circ} \mathrm{C} \text { y } \\
\text { usar en un plazo de } 6 \\
\text { horas, incluido cualquier } \\
\text { tipo de transporte a pie, } \\
\text { para evitar sacudidas y } \\
\text { vibraciones } \\
\text { No se puede trasportar } \\
\text { las jeringas cargadas ni } \\
\text { agitar el vial durante el } \\
\text { transporte ya diluido } \\
\text { Una vez descongela- } \\
\text { da, no puede volver a } \\
\text { congelarse } \\
\text { Conservar en el } \\
\text { embalaje original para } \\
\text { protegerlo de la luz. Los } \\
\text { viales descongelados } \\
\text { se pueden manipular } \\
\text { en condiciones de luz } \\
\text { ambiental }\end{array}$ & $\begin{array}{l}\text { Almacenamiento: Con- } \\
\text { servar en el embalaje } \\
\text { original para protegerlo } \\
\text { de la luz. } \\
2 \text { dosis de } 0,5 \mathrm{ml} \text {. NO SE } \\
\text { DILUYE } \\
\text { A partir de los } 18 \text { años }\end{array}$ & & $\begin{array}{l}\text { La vacuna se presenta como } \\
\text { un vial multidosis ( } 5 \text { dosis) } \\
\text { Los viales deben protegerse } \\
\text { de la luz } \\
\text { Una vez descongelada, no se } \\
\text { puede volver a congelar }\end{array}$ \\
\hline
\end{tabular}

\footnotetext{
* El vial abierto, desde un punto de vista microbiológico, se debe utilizar de manera inmediata después de la primera punción.
} 
de personas con discapacidad cognitiva o psicosocial pero con un grado de discapacidad que no les impide tomar una decisión, se informará mediante los formatos adecuados y contando con los apoyos necesarios para que la persona pueda tomar una decisión libre, en condiciones análogas a las demás ${ }^{22}$.

\section{Recursos materiales necesarios}

Para realizar la administración, por cada dosis a administrar:

- 1 aguja 22G o $23 \mathrm{G}$.

- 1 jeringa de "bajo volumen muerto" (significa que el espacio no tenga más de 35 microlitros, $0,035 \mathrm{~cm}^{3}$ ).

- Rollo de algodón o celulosa precortado en cuadrados o gasa.

- No se necesita antiséptico, salvo si la piel está visiblemente sucia (en este caso se lavará con agua y jabón).

- Alcohol al 70\%.

- Contenedor para residuos punzantes y productos biológicos.

- Material necesario para la dilución de Vacuna C0MIRNATY ${ }^{\circledR}$ (Pfizer-BioNTech)

- Jeringa de $2 \mathrm{ml}$ para dilución.

- Suero salino al 0,9\% en unidosis ( $2 \mathrm{ml})$, sin conservantes.

- Aguja para diluir de 216 o menor calibre.

\section{Equipo de Protección Individual (EPI) para la enfer- mera que vacuna ${ }^{27}$ :}

- Solución hidroalcohólica virida (Norma UNE-EN 14476: 2014+Al:2015)
- Guantes de nitrilo.

- Mascarrilla autofiltrante FFP2 (UNE-EN 149:2001 $+\mathrm{Al}: 2010)$

- Bata.

- Protección ocular.

- El local debe disponer de agua corriente y jabón para la higiene de manos.

- Se debe combinar las medidas preventivas ambientales con el EPP para prevenir la transmisión.

\section{Comprobaciones previas}

En la Tabla 2 se recogen las comprobaciones previas a realizar antes de administrar la vacuna ${ }^{22,28}$.

\section{Procedimiento}

1. Higiene de manos y colocación del EPI correspondiente.

2. Se prepara el material necesario para administrar las dosis que se sacarán de cada vial según el tipo de vacuna y se moviliza el vial según las indicaciones de la ficha técnica:

- Vial de la Vacuna COMIRNATY ${ }^{\circledR}$ (Pfizer-BioNTech):

- En el punto de vacunación, antes de diluir, con el vial a temperatura ambiente, voltear 10 veces, suavemente, sin agitar.

- Se coloca el material necesario para DILUIR un vial, es decir, se preparan jeringa de dilución (2 $\mathrm{ml}$ ), aguja de cargar (21G o menor calibre). Se retira la tapa del vial y se asegura no tocar con las manos el cierre del vial, el cual se debe desinfectar con alcohol al $70 \%$ antes de cada punción.

Tabla 2. Comprobaciones previas a la vacunación.

Comprobación de posibles contraindicaciones absolu-

tas o relativas a la vacunación

- ¿El paciente presenta, en este momento, signos o síntomas de la COVID-19?

- ¿El paciente presenta una ALERGIA GRAVE a: algún fármaco inyectable, medio de contraste, ¿alguna vacuna (incluida vacuna contra la COVID-19)?

- ¿El paciente ha recibido, en los últimos 3 meses, algunos de los siguientes tratamientos: corticoides, quimioterapia, radioterapia, inmunoglobulinas, transfusiones de sangre u otros hemoderivados, otros medicamentos que disminuyan la inmunidad

- ¿El paciente ha presentado una infección previa por SARSCoV-2?

- Si el paciente es una mujer: ¿Está embarazada o existe la posibilidad de que se quede embarazada en los 2 próximos meses? ¿Da lactancia materna?
Realizar una completa verificación antes de la administración, que asegure el cumplimento de las " $7 C$ "

1C: Paciente correcto: comprobar nombre, apellidos y fecha de nacimiento si se corresponde con los datos de su historia.

2C: Edad correcta: comprobar que tiene la edad adecuada para la vacuna a administrar.

3C: Vacuna correcta: comprobar que la vacuna a administrar es la que le corresponde según el motivo de vacunación y está en perfectas condiciones.

4C: Dosis correcta: comprobar que la dosis a administrar es la que le corresponde según su historia de vacunación. Comprobar los mililitros a administrar y el intervalo entre dosis.

5C: Vía de administración correcta: comprobar que utilizamos la vía de administración que corresponde a esa vacuna.

6C: Condiciones correctas: comprobar que la vacuna se encuentra en perfectas condiciones para su administración y su almacenamiento.

7C: Registro correcto: comprobar que el registro en su cartilla vacunal y en la historia clínica es el adecuado, antes y después del acto vacunal. 
- Con la jeringa de cargar se coge el vial mono dosis de suero salino de $1,8 \mathrm{ml}$, el resto del suero se desecha. Se inyecta el suero en el vial de la vacuna sin retirar la aguja y la jeringa, se iguala la presión dentro del vial, retirando $1,8 \mathrm{ml}$ de aire. Se vuelve a voltear suavemente el vial SIN AGITAR 10 veces.

- Vial de la Vacuna mRNA-1273 ${ }^{\circledR}$ (Moderna)

- En el punto de vacunación con el vial a temperatura ambiente, GIRAR el vial varias veces, suavemente, sin agitar ni voltear, después de la descongelación y antes de cada extracción. (Moderna Biotech Spain, S.L, 2020).

- Se prepara el material necesario para ADMINISTRAR las 10 dosis que se sacarán del vial: 10 jeringas con sus correspondientes agujas según el paciente. Se retira la tapa del vial y se asegura no tocar con las manos el cierre del vial, el cual se debe desinfectar con alcohol al $70 \%$ antes de cada punción.

- Vial de la Vacuna Vaxzevria ${ }^{\circledR}$ (AstraZeneca)

- Del vial de la "antigua AstraZeneca" también se extraen 10 dosis, por tanto, al preparar el material necesario para administrar se necesita: 10 jeringas con sus correspondientes agujas según el paciente. Se retira la tapa del vial y se asegura no tocar con las manos el cierre del vial, el cual se debe desinfectar con alcohol al $70 \%$ antes de cada punción.

- Vial de la Vacuna Ad26.COV2S ${ }^{\circledR}$ (Janssen)

- Se prepara el material necesario para ADMINISTRAR las dosis que se sacarán del vial: 5 jeringas con sus correspondientes agujas según el paciente. Girar el vial suavemente en posición vertical durante 10 segundos. No agitar. Se retira la tapa del vial y se asegura no tocar con las manos el cierre del vial, en el caso que se toque, se debe desinfectar.
3. Se inspecciona el aspecto de la vacuna tal como se recoge en la ficha técnica. (ver Tabla 3). Se anota fecha y hora en el vial para verificar el momento de su perforación.

4. Se extrae la dosis correspondiente a cada vial de cada tipo de vacuna, en una jeringa con aguja para inyección intramuscular (22G y 23G) con dispositivo de bioseguridad:

- La dosis de la Vacuna COMIRNATY ${ }^{\circledR}$ (Pfizer-BioNTech) es $0,3 \mathrm{ml}$.

- La dosis de la Vacuna mRNA-1273 ${ }^{\circledR}$ (Moderna) es de $0,5 \mathrm{ml}$.

- La dosis de la Vacuna Vaxzevria ${ }^{\circledR}$ (AstraZeneca) es de $0,5 \mathrm{ml}$.

- La dosis de la Vacuna Ad26.COV2S ${ }^{\circledR}$ (Janssen) es de $0,5 \mathrm{ml}$.

5. Punción intramuscular ${ }^{22}$ :

- La piel no precisa desinfección previa salvo que este visiblemente sucia (en ese caso se limpiará con suero salino o con agua y jabón).

- Elegir una zona de piel intacta, sin tatuajes y sin lesiones. No aplicar en lugares donde exista inflamación, dolor, anestesia ni vasos sanguíneos visibles.

- No se considera necesario hacer un aspirado previo a la inyección (ya que los vasos en los lugares recomendados no son del tamaño suficiente como para introducir la aguja en ellos), pero si se hace y se comprueba contenido hemático, debe retirarse y repetir la inyección.

- Debe procurarse la relajación de la musculatura en la que se vaya a inyectar.

- La enfermera palpa el borde inferior del acromion y coloca el pulgar en la parte inferior del músculo deltoides. Traza una línea imaginaria entre esos dos puntos y el lugar de punción es el punto medio donde realiza la inyección intramuscular. Tras la punción se ejerce una ligera presión durante dos minutos sin frotar.

Tabla 3. Comprobaciones del aspecto a inspeccionar de manera visual de cada vacuna, según la ficha técnica.

\begin{tabular}{l|c|c|c|c}
\hline $\begin{array}{l}\text { Tipo de Vacuna y } \\
\text { Fabricante }\end{array}$ & $\begin{array}{c}\text { COMIRNATY }{ }^{\circledR} \\
\text { Pfizer }\end{array}$ & $\begin{array}{c}\text { mRNA-1273 } \\
\text { Moderna }\end{array}$ & $\begin{array}{c}\text { Vaxzevria }{ }^{\circledR} \\
\text { Astra Zeneca }\end{array}$ & $\begin{array}{c}\text { Ad26.COV2.5 } \\
\text { Jassen }\end{array}$ \\
$\begin{array}{l}\text { La dispersión } \\
\text { descongelada puede } \\
\text { del vial antes de extraer } \\
\text { la dosis }\end{array}$ & $\begin{array}{c}\text { contener partículas } \\
\text { amorfas opacas de color } \\
\text { entre blanco y } \\
\text { blanquecino }\end{array}$ & $\begin{array}{c}\text { Dispersión de color entre } \\
\text { blanco y blanquecino }\end{array}$ & $\begin{array}{c}\text { La suspensión es } \\
\text { incolora a ligeramente } \\
\text { marrón, transparente a } \\
\text { ligeramente opaca }\end{array}$ & $\begin{array}{c}\text { Suspensión incolora a } \\
\text { ligeramente amarilla, } \\
\text { entre transparente y } \\
\text { muy opalescente }\end{array}$ \\
\hline
\end{tabular}


- Para la administración intramuscular se debe introducir la aguja en un ángulo de $90^{\circ}$ respecto a la piel.

- Se recomiendan dos tipos de técnicas:

- Técnica del aplanado: consiste en aplanar la piel y el tejido celular subcutáneo en el lugar de la inyección mediante un movimiento de separación entre pulgar e índice, al tiempo que se presiona sobre la masa muscular.

- Técnica del pellizco: consiste en coger el músculo entre los dedos índice y pulgar de la mano libre.

- La inyección con aguja de calibre normal debe ser rápida; si se usan agujas de menor calibre, la inyección debe ser menos rápida (unos 5 segundos) para evitar un trauma añadido al tejido muscular.

- Si el paciente presenta linfedema, fístula arteriovenosa, quemaduras, hematomas, catéteres vasculares, prótesis vasculares o poca masa muscular en el deltoides, se elegiría la otra extremidad superior 0 una vía alternativa es la cara anterolateral externa del muslo (tercio medio del músculo vasto externo 0 lateral) $22,23,29$.

6. El usuario debe ejercer presión en el lugar de inyección (sin frotar) durante 2 minutos9,23. Se realiza higiene de manos y cambio de guantes. El vial y la aguja se desechan en el contenedor para residuos punzantes y productos biológicos. Se deberá desinfectar los posibles derrames con agentes que contengan actividad viricida frente adenovirus.

7. Se indica al paciente que debe permanecer en la zona de observación determinada al menos 15 minutos. Si reacciones alérgicas graves previas, deberá esperar 30 minutos por su seguridad?.

8. Se realiza el registro de la vacuna en la historia clínica del usuario (incluyendo tipo de vacuna, lote y grupo de la estrategia de vacunación).

\section{Advertencias y precauciones}

Como precaución, las personas con antecedentes de alergia grave (anafilaxia) a otras vacunas o terapias administradas por vía muscular deben recibir información sobre la posibilidad del riesgo de reacción alérgica grave tras recibir la vacuna.

Las personas en tratamiento crónico con anticoagulantes, que mantengan controlado y estable el INR, pueden recibir la vacunación intramuscular. La inyección se realizará con una aguja de 23G. En caso de duda debe consultarse con el profesional clínico responsable de su tratamiento, ${ }^{83}$.

El individuo que recibe tratamiento para reducir el sangrado (por ejemplo hemofilia) la vacunación intramuscular se puede programar poco después de la administración del tratamiento, seguida de una presión firme aplicada en el sitio ( $\sin$ frotar) durante al menos mínimo 2 minutos ${ }^{8,23}$.

Fertilidad, Embarazo o Lactancia: la actualización 7 de la EVCCISE propone vacunar a las embarazadas 0 en periodo de lactancia con vacunas de ARN mensajero cuando les corresponda según el grupo de priorización al que pertenezcan ${ }^{18}$.

Inmunodepresión: los pacientes inmunodeprimidos han sido incluidos en la EVCCISE dentro del grupo 7 (Personas con condiciones de muy alto riesgo $)^{18}$.

Contraindicaciones: alérgicos al ácido cítrico monohidrato, citrato trisódico dihidrato u otros excipientes susceptibles de declaración obligatoria (ver Tabla 4) y anafilaxia previa. No existen estudios de compatibilidad con otros medicamentos.

\section{Vacunación de personas con infección previa por SARS-CoV-2 ${ }^{9}$}

- Personas de 65 o menos años de edad con diagnóstico de infección por SARS-CoV-2 antes de recibir

Tabla 4. Excipientes susceptibles de declaración obligatoria según la Agencia Española del Medicamento de cada vacuna ${ }^{12,14,16,20}$.

\begin{tabular}{|c|c|c|c|c|}
\hline $\begin{array}{l}\text { Tipo de Vacuna y } \\
\text { Fabricante }\end{array}$ & $\begin{array}{l}\text { COMIRNATY } \\
\text { Pfizer }\end{array}$ & $\begin{array}{l}\text { mRNA-1273 } \\
\text { Moderna }\end{array}$ & $\begin{array}{l}\text { Vaxzevria }^{\circledR} \\
\text { Astra Zeneca }\end{array}$ & $\begin{array}{c}\text { Ad26.COV2.5 } \\
\text { Jassen }\end{array}$ \\
\hline Excipientes & $\begin{array}{l}\text { - Sacarosa } \\
\text { - Cloruro de sodio } \\
\text { - Cloruro potasico } \\
\text { - Hidrogenofosfato de } \\
\quad \text { sodio Dihidrato }\end{array}$ & $\begin{array}{l}\text { - Acetato de sodio trihidrato } \\
\text { - Sacarosa } \\
\text { - 1,2-dimiristoil-rac-glicero-3- } \\
\text { metoxipolietilen glicol-2000 } \\
\text { (PEG } 2000 \text { DMG) }\end{array}$ & $\begin{array}{l}\text { - Cloruro de sodio } \\
\text { - Edetato disodico } \\
\text { dihidratado } \\
\text { - Sacarosa } \\
\text { - Alcohol etilico } \\
\text { anhidro }\end{array}$ & $\begin{array}{l}\text { - Hidroxipropil-beta- } \\
\text { ciclodextrina } \\
\text { - Alcohol etilico } \\
\text { anhidro } \\
\text { - Cloruro de sodio } \\
\text { - Hidroxido de sodio } \\
\text { (e-524) }\end{array}$ \\
\hline
\end{tabular}


la primera dosis: se administrará una sola dosis al menos seis meses desde el padecimiento o el diagnóstico de infección. En caso de que se administre antes de haber transcurrido esos seis meses, la dosis se considerará válida y no será necesario administrar más dosis.

- Personas de 65 o menos años de edad con diagnóstico de infección por SARS-CoV-2 después de haber recibido la primera dosis: se administrará una segunda dosis transcurridos seis meses desde el padecimiento o el diagnóstico de infección.

- Personas mayores de 65 años con diagnóstico de infección por SARS-CoV-2 antes de recibir la primera dosis: se administrará una pauta de dos dosis. No se esperarán seis meses tras la infección para la administración de la primera dosis.

- Personas mayores de 65 años con diagnóstico de infección por SARS-CoV-2 después de haber recibido la primera dosis: se completará la pauta con una segunda dosis cuando estén completamente recuperadas y haya finalizado el período de aislamiento, garantizando el intervalo aconsejado entre dosis. No se esperarán seis meses tras la infección para la administración de la segunda dosis.

La vacuna de Janssen no se utilizará en personas que por antecedente de infección por SARS-CoV-2 solo precisen una dosis?.

Administración con otras vacunas: en los estudios clínicos, los participantes debían respetar un intervalo mínimo de 14 días antes y después de la administración de una vacuna antigripal para recibir la vacuna frente a COVID-19. Como norma general, se recomienda dejar un intervalo de al menos 7 días antes y después entre la administración de la vacuna frente a COVID-19 y cualquier otra ${ }^{30}$.

\section{Precauciones especiales en pacientes con ERCA}

Los pacientes en tratamiento con hemodiálisis, pueden ser vacunados en el contexto del procedimiento en su centro (antes o después de la sesión de hemodiálisis), sin necesidad de cambiar el régimen de anticoagulación ${ }^{31}$. Si el paciente es portador de una fístula arteriovenosa o un catéter venoso central, se elegirá como lugar de punción la otra extremidad superior, o en su defecto la cara anterolateral externa del muslo (tercio medio del músculo vasto externo o lateral) 22,23,29. Por las similitudes en su patogenia del síndrome de trombosis con trombocitopenia con la trombocitopenia inducida por heparina, y hasta que se disponga de mayor evidencia, se desaconseja la administración de las vacunas de vectores de adenovirus (Vaxzevria y Janssen) en personas con antecedente de trombocitopenia inducida por heparina ${ }^{18}$.

Los pacientes con ERC avanzada, con tratamiento inmunosupresor o no, suelen presentar tasas más bajas de seroconversión, bajos títulos de anticuerpos y una menor respuesta inmunitaria con las distintas vacunas, si se les compara con la población general ${ }^{32}$. Esto también ocurre en los pacientes trasplantados de riñón, en los que como consecuencia de la inmunosupresión inducida por el tratamiento, es posible que la respuesta a la vacuna sea atenuada en su magnitud y duración en comparación con la población general ${ }^{31}$.

Se recomienda la vacunación de todos los pacientes en lista de espera de trasplante. En aquellos pacientes que se encuentren en situación de espera para trasplante de vivo, es deseable que completen la vacunación un mes previo al trasplante (como mínimo 2 semanas antes). En pacientes recién trasplantados, se recomienda esperar un mes para su vacunación. En todo paciente que haya recibido timoglobulina o rituximab en el trasplante, se recomienda diferir la vacunación hasta el tercer mes post-trasplante. Si se ha administrado tratamiento para el rechazo (bolos de metilprednisolona, recambio plasmático terapéutico, gammaglobulina) se recomienda diferir 2 semanas la vacunación ${ }^{31}$.

\section{Conclusiones}

La evidencia científica avala que la ERC constituye un factor de riesgo importante para desarrollar enfermedad grave durante infección por SARS-CoV-2. Según los últimos protocolos, aunque cualquiera de las vacunas autorizadas por EMA son seguras para administrar a esta población de riesgo, se utilizaran preferentemente vacunas de ARNm.

Debemos de asegurarnos de dar información específica e individual en relación con las necesidades de cada paciente, incidiendo en todas aquellas situaciones que puedan sobreañadir incertidumbre en el mismo como pueden ser historia previa de alergia o anafilaxia, tratamiento previo con anticoagulantes o embarazo.

Es necesario conocer los antecedentes de cada paciente en relación con el contacto con el SARS-CoV-2, para asegurar una correcta inmunización.

En paciente sometidos a hemodiálisis no se recomienda la administración de las vacunas de vectores de adeno- 
virus por las semejanzas en su patogenia del síndrome de trombosis con trombocitopenia con la trombocitopenia inducida por heparina.

Los pacientes con ERC avanzada, suelen presentar tasas más bajas de seroconversión, bajos títulos de anticuerpos y una menor respuesta inmunitaria con las diferentes vacunas en comparación con la población general. Es necesario tener en cuenta las distintas situaciones relacionadas con el trasplante renal y tratamiento inmusupresor, para administrar la vacuna en el momento adecuado.

Debemos de garantizar una correcta conservación y reconstitución de las vacunas.

Recepción: 01-05-21

Aceptación: 07-06-21

Publicación: 30-06-21

\section{Bibliografía}

1. Ortiz A, Cozzolino M, Duivenvoorden R, Fliser D, Fouque $D$, Franssen CFM, et al. Chronic kidney disease is a key risk factor for severe COVID-19: A call to action by the ERA-edta. Nephrol Dial Transplant. 2021;36(1):87-94.

2. Clark $A$, Jit $M$, Warren-Gash $C$, Guthrie $B$, Wang HHX, Mercer SW, et al. Global, regional, and national estimates of the population at increased risk of severe COVID-19 due to underlying health conditions in 2020: a modelling study. Lancet Glob Heal. 2020;8(8):e1003-17.

3. Williamson EJ, Walker AJ, Bhaskaran K, Bacon S, Bates $C$, Morton $C E$, et al. Factors associated with COVID-19-related death using OpenSAFELY. Nature. 2020;584(7821):430-6.

4. Sociedad Española de Enfermería Nefrológica. Posicionamiento de la Sociedad Española de Enfermería Nefrológica (SEDEN) ante la vacunación de SARS-COV2 de las personas con enfermedad renal [Internet]. [consultado 3 mar 2021]. Disponible

en: https://www.seden.org/noticias/posicionamiento-de-la-sociedad-espanola-de-enfermeria-nefrologica-seden-ante-la.

5. Sánchez-Álvarez E, Quiroga B, de Sequera P. Posicionamiento de la Sociedad Española de Nefrología ante la vacunación frente al SARS-CoV-2. Nefrología. 2021;(En prensa).

6. The Renal Association. COVID-19 vaccination for adult patients with kidney disease: a position statement from the UK renal community [Internet]. [consultado 3 mar 2021]. Disponible en: https:// renal.org/health-professionals/covid-19/ra-resources/covid-19-vaccination-adult-patients-kidneydisease.

7. Statement on Kidney Patient Prioritization for COVID-19 Vaccines and Therapeutics. National Kidney Foundation [Internet]. 2020 [consultado 3 mar 2021]. Disponible en: https://www.kidney.org/ news/statement-kidney-patient-prioritization-covid-19-vaccines-and-therapeutics.

8. Grupo de Trabajo Técnico de Vacunación COVID-19 de la Ponencia de Programa y Registro de Vacunaciones. Actualización 5. Estrategia de vacunación frente a COVID-19 en España [Internet]. 2021 [consultado 3 abr 2021]. Disponible en: https://www.mscbs.gob. es/profesionales/saludPublica/prevPromocion/vacunaciones/covid19/docs/COVID-19_Actualizacion5_ EstrategiaVacunacion.pdf.

9. Grupo de Trabajo Técnico de Vacunación COVID-19 de la Ponencia de Programa y Registro de Vacunaciones. Actualización 6. Estrategia de vacunación frente a COVID19 en España [Internet]. 2021 [consultado 3 abr 2021]. Disponible en: https://www.mscbs.gob. es/profesionales/saludPublica/prevPromocion/vacunaciones/covid19/docs/COVID-19_Actualizacion6_ EstrategiaVacunacion.pdf.

10. Creech CB, Walker SC, Samuels RJ. SARSCoV-2 Vaccines. JAMA - J Am Med Assoc. 2021;325(13):1318-20.

11. de Francisco AL. Vacunas SARS-COV2 marzo 2021. En: Nefrología al Día [Internet]. Madrid: Sociedad Española de Nefrología; 2021 [consultado 3 abr 2021]. Disponible en: https://www.nefrologiaaldia.org/es-articulo-vacunas-sars-cov2-marzo-2021-366. 
12. Agencia Española del Medicamento. Vacuna Cominarty ${ }^{\circledR}$ Ficha Técnica [Internet] [consultado $3 \mathrm{abr}$ 2021]. Disponible en: https://cima.aemps.es/cima/ pdfs/ft/1201528001/FT_1201528001.pdf.

13. European Medicines Agency. Comirnaty. Ficha técnica. [Internet]. 2021 [consultado 28 may 2021]. Disponible en: https://www.ema.europa.eu/en/medicines/human/EPAR/comirnaty.

14. Agencia Española del Medicamento. COVID-19 Vaccine Moderna ${ }^{\circledR}$ Ficha técnica [Internet] [consultado 8 may 2021]. Disponible en: https://cima.aemps.es/ cima/pdfs/ft/1201507001/FT_1201507001.pdf.

15. European Medicines Agency. COVID-19 Vaccine Moderna. Ficha técnica [Internet]. 2021 [consultado 28 may 2021]. Disponible en: https://www.ema.europa. eu/en/medicines/human/EPAR/covid-19-vaccine-moderna.

16. Agencia Española del Medicamento. Vacuna Vaxzevria $^{\circledR}$ Ficha técnica [Internet]. Disponible en: https://cima.aemps.es/cima/pdfs/ft/1211529001/ FT_1211529001.pdf.

17. European Medicines Agency. Vaxzevria (previously COVID-19 Vaccine AstraZeneca). Ficha técnica [Internet]. 2021 [consultado 28 may 2021]. Disponible en: https://www.ema.europa.eu/en/medicines/ human/EPAR/vaxzevria-previously-covid-19-vaccine-astrazeneca.

18. Grupo de Trabajo Técnico de Vacunación COVID-19 de la Ponencia de Programa y Registro de Vacunaciones. Actualización 7. Estrategia de vacunación frente a COVID-19 en España [Internet]. 2021. Disponible en: https://www.mscbs.gob.es/profesionales/saludPublica/prevPromocion/vacunaciones/covid19/docs/COVID-19_Actualizacion7_EstrategiaVacunacion.pdf.

19. Informe del comité de bioética de España acerca de los fundamentos éticos legalesde permitir a las personas menores de sesenta años que han sido vacunados con primera dosis de vaxzevria, vacunarse, en segunda dosis, con la misma vacuna. Comité de Bioética de España; 2021.

20. Agencia Española del Medicamento. Vacuna Ad26. COV2S ${ }^{\circledR}$ Ficha técnica [Internet]. [consultado 28 may 2021]. Disponible en: https://cima.aemps.es/ cima/pdfs/ft/1201525001/FT_1201525001.pdf.
21. European Medicines Agency. COVID-19 Vaccine Janssen. Ficha técnica [Internet]. 2021 [consultado 28 may 2021]. Disponible en: https://www.ema.europa.eu/en/medicines/human/EPAR/covid-19-vaccine-janssen.

22. Comité Asesor de Vacunas (CAV-AEP). Manual de Vacunas en línea de la Asociación Española de Pediatría [Internet]. Madrid; 2020. [consultado 3 abr 2021]. Disponible en: https://vacunasaep.org/documentos/manual/manual-de-vacunas.

23. Public Health England. COVID-19 vaccination programme. Information for healthcare practitioners [Internet]. 2021 [consultado 20 may 2021]. Disponible en: https://assets.publishing.service.gov.uk/government/uploads/system/uploads/attachment_data/ file/985170/COVID-19_vaccination_programme guidance_for_healthcare_workers_11_May_2021_ v3.6.pdf.

24. Health and Safety Executive. Guidance on respiratory protective equipment fit testing [Internet]. Norwich: Health and Safety Executive; 2019 [consultado 3 abr 2021]. 1-14. p. Disponible en: https://www.hse.gov. uk/pubns/indg479.pdf.

25. Matharu K. Beards and masks. Vol. 228, British Dental Journal. Springer Nature; 2020. p. 814.

26. Ministerio de Salud Argentina. Sostenimiento de la vacunación de calendario en contexto de pandemia [Internet]. 2020 [consultado 8 may 2021]. Disponible en: https://bancos.salud.gob.ar/sites/default/ files/2020-09/covid19-sostenimiento-de-vacunacion-de-calendario-en-contexto-de-pandemia.pdf.

27. Banco de Preguntas Preevid. Protección para los profesionales sanitarios que administran las vacunas contra COVID-19 [Internet]. MurciaSalud; 2021 [consultado 8 may 2021]. Disponible en: http://www.murciasalud.es/preevid /23991.

28. Australian Technical Advisory Group on Immunisation (ATAGI). The Australian Immunisation Handbook [Internet]. Australian Government Department of Health, editor. Canberra; [consultado 8 may 2021]. Disponible en: https://immunisationhandbook.health. gov.au/. 
29. Banco de Preguntas Preevid. ¿Estan contraindicadas las inyecciones intramusculares en pacientes anticoagulados con Sintrom ${ }^{\circledR}$ ? [Internet]. MurciaSalud; 2015 [consultado 3 mar 2021]. Disponible en: http:// www.murciasalud.es/preevid/20784.

30. Fisterra. Vacuna del COVID-19 [Internet]. 2021. [consultado 8 may 2021] Disponible en: https://www. fisterra.com/covid-19/ficha.asp?idficha=3204.

31. Silvariño R, Ferreiro A, Seija M, Boggia J, Luzardo $L, 0$ tatti $G$, et al. Recomendaciones sobre la vacunación contra SARS-CoV-2/COVID-19 en pacientes con enfermedad renal crónica y trasplante renal. Nefrol Latinoam. 2021;37(2):13-22.

32. Rico-Fontalvo J, Daza-Arnedo R, Leal-Martinez V, Pájaro-Galvis N, Abuabara-Franco E, Pérez-Calvo C, et al. Vacunación en pacientes con enfermedad renal crónica. Arch Med. 2021;17(1):6.

Este artículo se distribuye bajo una Licencia Creative Commons Atribución-NoComercial 4.0 Internacional. https://creativecommons.org/licenses/by-nc/4.0/

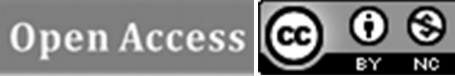

